\title{
Explorando a retenção de informações sobre contracepção a partir de diferentes usos da linguagem gráfica
}

\author{
Exploring the retention of information about contraception from \\ different uses of graphic language
}

Caroline Winkelmann, Gabriela Botelho Mager

Design da informação, psicologia cognitiva, retenção de informação

\begin{abstract}
Buscando avaliar se, e caso sim, como, diferentes usos da linguagem gráfica podem interferir na retenção da informação, foi desenvolvido um protocolo usando a análise combinada de dados coletados com uso do equipamento Eye-Tracker SMI e entrevistas semiestruturadas. Com isto, foi possível explorar se a atenção, a compreensão e a percepção de informação sobre contracepção resultavam em diferentes níveis de retenção da informação vista por parte de um público de jovens adultas a depender do tipo de linguagem gráfica usada nas peças gráficas do estudo. Do desenvolvimento, teste, correção e aplicação deste protocolo saíram percepções das possibilidades e desafios na avaliação de algo tão subjetivo quanto a memória e tão delicado quanto a educação sexual, e como estes podem estar relacionados a como informações são apresentadas em uma peça gráfica estática e digital. Este artigo descreve, por fim, os caminhos traçados no desenvolvimento e aplicação desta pesquisa a fim de partilhar o que foi encontrado e expor indícios relevantes sobre a comunicação de saúde sexual.
\end{abstract}

Information design, cognitive psychology, retention of information

In order to assess whether, and if so, how different uses of graphic language can interfere with the retention of information, a protocol was developed using the combined analysis of data collected using the Eye-Tracker SMI equipment and semi-structured interviews. The objective was to understand whether the attention, understanding and perception of information about contraception resulted in different levels of information retention seen by an audience of young adults depending on the type of graphic language used in the graphic pieces of the study. From the development, testing, correction and application of this protocol came perceptions of the possibilities and challenges in the evaluation of something as subjective as memory and as delicate as sex education, and how these can be related to how information is presented in a static graphic piece and digital. Finally, this article describes the paths traced in the development and application of this research in order to share what was found and expose relevant evidence on sexual health communication.

\section{Introdução}

O design da informação agrega conhecimentos com o propósito de transformar dados complexos (ou em grande quantidade) em informações acessíveis, objetivas e compreensíveis para um público. Pettersson (2012) considera que aspectos gráficos e estéticos são especialmente relevantes tendo em vista que a percepção e atenção interferem na

Anais do $10^{\circ} \mathrm{CIDI}$ e $10^{\circ} \mathrm{CONGIC}$

Kelli C.A.S. Smythe, Rafael de Castro Andrade (orgs.)

Sociedade Brasileira de Design da Informação - SBDI

Curitiba | Brasil | 2021
Proceedings of the $10^{\text {th }} \mathrm{CIDI}$ and $10^{\text {th }}$ CONGIC

Kelli C.A.S. Smythe, Rafael de Castro Andrade (orgs.)

Sociedade Brasileira de Design da Informação - SBDI Curitiba | Brazil | 2021 
memorização de uma informação. Isso se sustenta com a complementação de Mourão Júnior e Faria (2015), afirmando que as funções psicológicas se interpolam ao invés de agirem isoladas entre si. Preece et al. (2013) e Shedroff (1999) debatem ainda que o conhecimento de um indivíduo é gerado por processos internos integrados com percepções do mundo exterior (em materiais gráficos, por exemplo), sendo esta integração a chave para mensagem de informações.

Peças gráficas de saúde, sejam bulas e embalagens medicamentosas, infográficos jornalísticos, ou cartazes de uma campanha pública de nível nacional, comunicam informações especialmente relevantes. A atenção, despertar de curiosidade, e percepção dos elementos afeta não só a própria compreensão, como a memorização das informações dispostas (Pettersson, 2012), e o conhecimento se consolida com a integração da apresentação da informação com a mente do público que a recebe (Preece et al., 2013; Shedroff, 1999).

Para uma informação ser rememorada, é essencial que no seu período de aquisição isto seja feito da maneira mais eficiente possível. A etapa de aquisição acontece a partir do despertar da atenção percepção e atenção. Dada a aquisição, é possível evocar um conhecimento, registrado na memória de curto prazo, ou na operacional, sendo possível lembrar dessa informação por pouco tempo, cerca de 30 segundos. Há plena memorização de um conhecimento quando este nos retorna a longo prazo, ou seja, há a consolidação deste (Mourão Júnior \& Faria, 2015; Sternberg, 2010). Mourão Júnior e Faria (2015) e Sternberg (2010) defendem ainda que a memória funciona como um repositório e como um construtor de conhecimentos, visto que funciona de maneira reconstrutiva e interdependente com os demais processos mentais, afetando nossa percepção de novas informações.

Dito isto, o presente artigo apresenta a convergência de estudos de memória de psicólogos cognitivos com o design da informação - mais especificamente, linguagem visual - para avaliar como estas podem interferir na retenção de informações sobre contracepção. Muito ainda não se sabe sobre a memória, porém é reconhecido que não codificamos informações por apenas uma via sensorial. A pergunta é, então, como codificamos essas informações? (Sternberg, 2010). Poderiam diretrizes do design da informação auxiliar na retenção de informações sobre contracepção? Como a percepção de uma peça gráfica interfere na retenção da informação apresentada? E como o repertório anterior influencia na percepção de novas informações?

\section{Design e cognição}

O Design da Informação é uma disciplina vinda do Design Gráfico, que busca "organizar e apresentar dados em informações valiosas e significativas" (Shedroff, 1999). Katz (2012) comenta que o trabalho do designer de informação é projetar com intenção, para que os objetos funcionem não para o designer, e sim para quem o objeto projetado é direcionado. $\mathrm{O}$ autor complementa que o trabalho do designer de informação é simplificar, deixar as informações acessíveis para as pessoas que precisam daquela informação tomarem decisões com segurança e certeza. 
Shedroff (1999) defende que o processo da aquisição de conhecimento acontece através da integração de um estímulo externo e a mente de um indivíduo (figura 1), ou seja, a apresentação da informação gera um estímulo que pode, internamente, ser transformado em conhecimento, e posteriormente em sabedoria. Preece et al. (2013) comentam algo similar, salientando que apesar dos processos cognitivos serem internos, eles se sucedem por estímulos externos, como livros, a internet, diagramas, jornais, ilustrações, etc. O que cabe a designers é a produção das peças gráficas, podendo colaborar com a aquisição de conhecimentos através desta integração. No campo da psicologia cognitiva, este processo cognitivo entre a percepção de uma informação e sua integração na memória de um usuário é o que Sternberg (2010) chama de "codificação e armazenamento".

Figura 1: diagrama do processo integrativo da aquisição de conhecimento proposto por Shedroff (1999). No diagrama, produtores são os transmissores da informação, enquanto consumidores são os receptores da informação. Fonte: elaboração das autoras com base em Shedroff (1999).

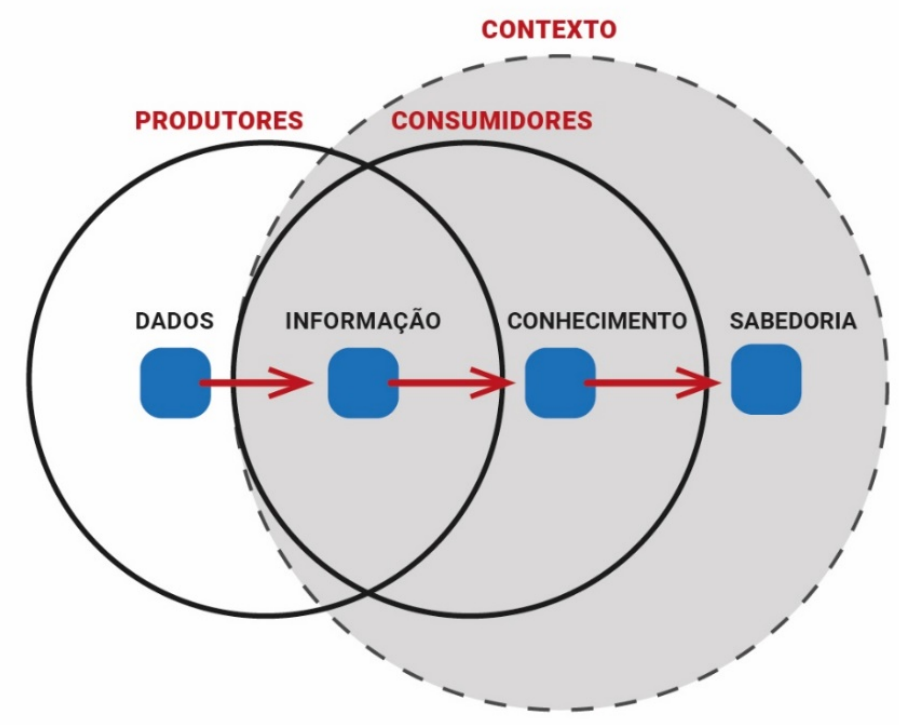

De acordo com Redig (2004), o Design da Informação é uma área de alta relevância pois trabalha o design de forma expressiva para questões públicas: procurando garantir a informação clara, precisa e verdadeira. E nisto a estética para o design da informação é usada como uma ferramenta para a clareza, direcionamento e organização da informação, ou seja, não se ignora a importância das questões estéticas para percepção e compreensão das informações (Pettersson, 2012; Shedroff, 1999).

\section{Memória}

Apesar de haver separação nos estudos em psicologia para fins didáticos, funções cognitivas não acontecem isoladamente, ou seja, a memorização acontece em paralelo com processos de atenção, percepção, motivação, etc., e a consolidação de uma informação na memória de 
longo prazo depende também da percepção desta no momento da aquisição (Mourão Júnior \& Faria, 2015; Pettersson, 2012; Sternberg, 2010).

"Memória" é definida como "a capacidade que os seres vivos têm de adquirir, armazenar e evocar informações." (Mourão Júnior \& Faria, 2015). De acordo com Sternberg (2010), os psicólogos cognitivos se referem a três operações comuns da memória: codificação, armazenamento e recuperação. Sobre estes estágios, o autor diz que:

Codificação refere-se a como você transforma um dado físico e sensorial em um tipo de representação que pode ser localizado na memória. Armazenamento refere-se ao modo como você retém as informações codificadas. Recuperação refere-se à maneira como você ganha acesso às informações armazenadas na memória. (p. 189-190)

De acordo com Mourão Júnior e Faria (2015), o armazenamento de informação pode ser dividido em três subprocessos: a) aquisição: o momento em que a informação chega até o sistema nervoso, pelas vias sensoriais, e é enviada até o cérebro; b) consolidação: referente ao armazenamento da informação no cérebro, seja na memória de curto ou de longo prazo, isso a depender do tipo de informação e estímulo dado; e c) evocação: acontece quando há retenção da informação, tornando-se uma informação memorizada, que pode ser acessada novamente, seja por recordação ou por reconhecimento.

Segundo Sternberg (2010), podemos observar dois tipos de memorização:

1. Memória explícita: como recordações, são informações, fatos e aprendizados disponíveis em nosso repertório mental;

2. Memória implícita: uma lembrança intrínseca, subconsciente, que apesar de não se manifestar em nossa mente é usada diariamente nos demais processos.

Por exemplo, durante a leitura usamos da memória implícita pois é uma ação que recordamos de maneira automática e subconsciente, sem recorrer à memória de um "passo a passo" do ato, está memorizado em nosso cérebro como se lê. Seguindo a mesma ideia para exemplificar a memória explícita, uma recordação desta categoria seria um livro cuja leitura foi apreciada, seu enredo, personagens e até frases que mais gostamos. Segundo Mourão Júnior e Faria (2015), estas duas classificações de memória são subcategorias da memória de longa duração. Na memória de longa duração são armazenadas informações por meses, anos e até décadas, e por isto, ela pode ser chamada também de memória remota.

As operações de memória colocadas acima introduzem conceitos vistos no modelo clássico de memória proposto por Richard Atkinson e Richard Shiffrin em 1968. Sternberg (2010) explica que os autores propuseram um modelo de memória com três sistemas de armazenamento:

1. Armazenamento sensorial, que estoca quantidades limitadas de informação por um período muito breve;

2. Armazenamento de curto prazo, que estoca informações por períodos um pouco maiores, porém ainda limitado; 
3. Armazenamento de longo prazo, grande capacidade de armazenamento, onde as informações ficam estocadas por períodos longos, com possibilidade de não haver limite de tempo de estocagem.

Este modelo organiza o processo da memória em três receptáculos que trabalham para a retenção das informações. Atualmente, porém, psicólogos cognitivos podem nomear estes receptáculos de maneiras distintas, de acordo com Sternberg (2010), sendo chamados de memória sensorial, memória de curto prazo e memória de longo prazo, respectivamente. O funcionamento dos receptáculos do modelo de memória clássico pode ser visualizado no esquema da figura 2, a seguir:

Figura 2: modelo de memória clássico de Atkinson- Shiffrin (1968) apud Sternberg (2010). Fonte: elaboração das autoras com base em Sternberg (2010).

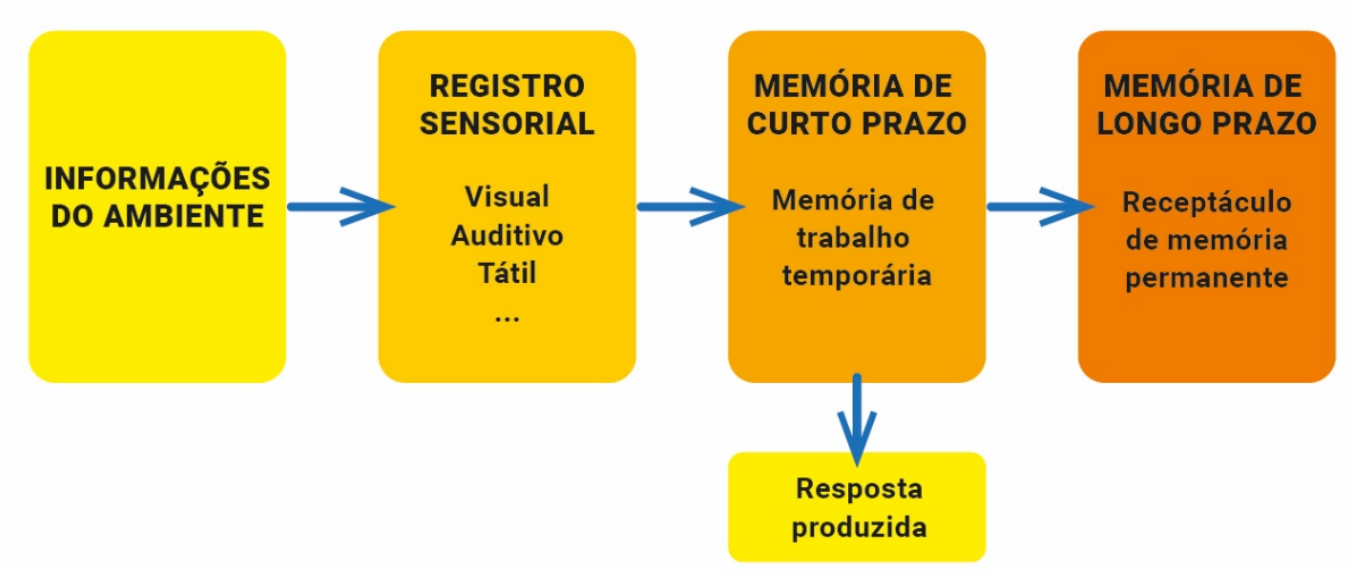

Segundo Sternberg (2010) e Correa e Gorenstein (1988), o processo de retenção de informações acontece quando informações presentes na memória de curto prazo são gradativamente transferidas para a memória de longo prazo. Casos em que o sujeito não recupera uma informação após vinte minutos corridos da exposição a esta, se considera que não houve retenção da informação (Correa \& Gorenstein, 1988). Se uma peça gráfica pretende informar algo que deve ser lembrado, é relevante entender como acontece este processo de retenção da informação.

Retornando ao que é discutido por Shedroff (1999), vale frisar que:

Assim como os dados podem ser transformados em informações significativas, as informações podem ser transformadas em conhecimento e, depois, em sabedoria. O conhecimento é um fenômeno que podemos construir para os outros, assim como podemos construir informações para os outros a partir de dados. (p. 271, tradução nossa)

E neste ponto, Sternberg (2010) contribui ao afirmar que sem uma elaboração que contextualize a informação, esta não pode ser organizada e transferida para a memória de longo prazo. É importante destacar ainda que a memória serve não apenas como repositório 
de conhecimento, mas, também, como um construtor deste (Mourão Júnior \& Faria, 2015; Sternberg, 2010). Isto acontece, defendem os autores, porque os processos cognitivos acontecem de maneira interdependente, e a memória pode funcionar de maneira reconstrutiva, afetando a nossa percepção de novas informações.

\section{Linguagem gráfica}

Twyman (1985) se dedicou a resolver questões de linguagem voltadas para o design gráfico. 0 autor afirma que a linguística não apurava a linguagem gráfica ao esquematizar a divisão da linguagem, considerando apenas a linguagem verbal, enquanto designers consideravam a verbal e pictórica. Com essa constatação, o autor apresentou uma nova proposta de esquema da linguagem que unisse a visão de designers e linguistas (Twyman, 1985). Com isto, o autor propõe o esquema apresentado na figura 3 , considerando os canais de linguagem para distinção destas, sendo estes canais a visão e audição.

Figura 3: modo esquemático proposto por Twyman (1985). Fonte: elaboração das autoras, baseado em Twyman (1985).

\section{CANAL MODO}

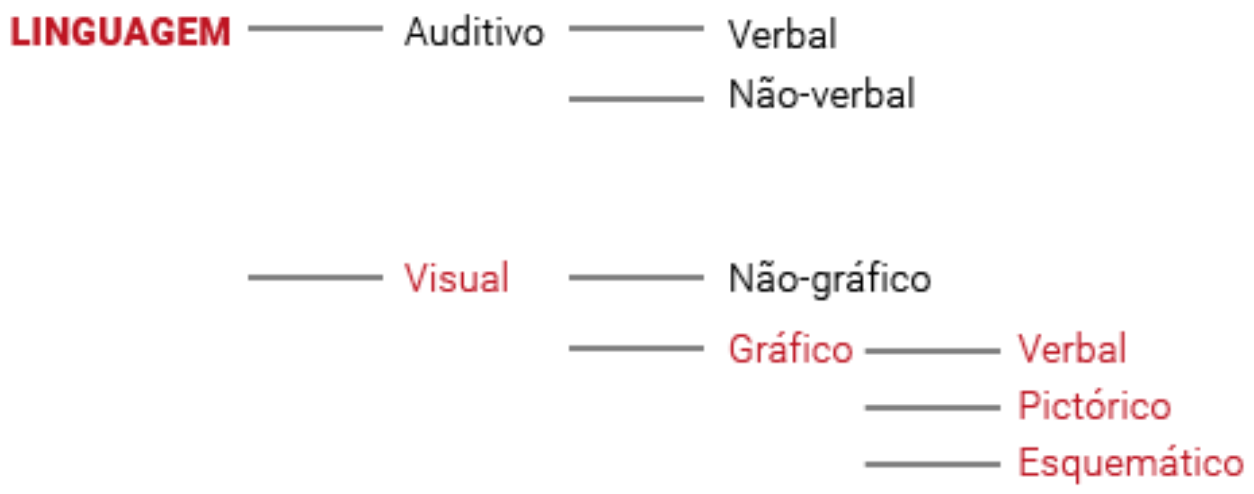

O autor também propôs um esquema para classificação gráfica verbal (figura 4, abaixo). De acordo com Twyman (1979), esta matriz é uma tentativa de abraçar as variações da linguagem gráfica. $E$, sendo todos nós consumidores e criadores de linguagem gráfica em algum nível (Twyman, 1979), para compreendê-la é relevante a categorização de todas as formas que a comunicação visual pode tomar. 
Figura 4: esquema em matriz de Twyman (1979). Fonte: elaboração das autoras a partir do modelo de Twyman (1979).

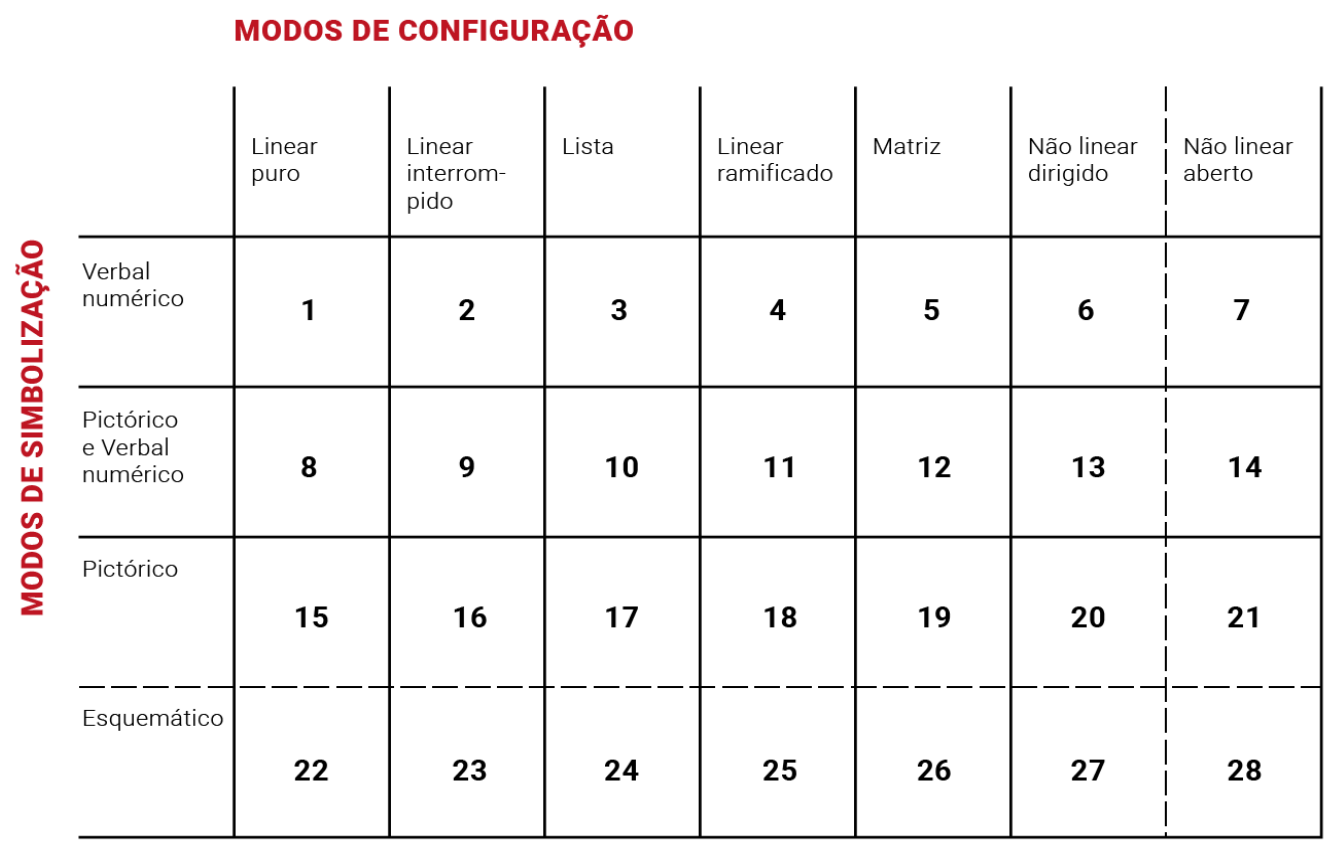

A matriz de Twyman (1979) é configurada pelo cruzamento do modo de simbolização versus o modo de configuração de uma peça gráfica, que se resumidamente assim se caracterizam:

\section{Modos de Simbolização}

Tipo de comunicação visual da imagem, seja número, palavra, imagens pictóricas ou esquemáticas.

- Verbal numérico: palavras e/ou números;

- Pictórico e Verbal numérico: imagens pictóricas com números e/ou palavras;

- Pictórico: imagens pictóricas, incluindo fotografia e desenhos de qualquer estilo;

- Esquemático: gráficos e o que mais não for verbal ou pictórico.

\section{Modos de configuração}

Diferentes maneiras de organizar a informação no espaço da peça gráfica, seja esta configuração um esquema, tabela, com direcionamento ou de "leitura livre" dos elementos dispostos. Um exemplo dado por Twyman (1979) é o rotineiro uso do modo de configuração não linear dirigido por peças publicitárias, onde o olhar do leitor é atraído simultaneamente por mais de um elemento da imagem. 


\section{Explorando a retenção de informação}

A partir do referencial apresentado, para esta pesquisa foram investigadas peças gráficas informativas e estáticas cujo conteúdo fosse contracepção e/ou saúde sexual encontradas nos sites Drauzio Varella e Revista Saúde, além do perfil oficial no Facebook do Ministério da Saúde no triênio de 2015 a 2018. Como "saúde sexual" compreenderam-se tópicos sobre prevenção de Infecções Sexualmente Transmissíveis (IST), e métodos de esterilização masculina e feminina (vasectomia e laqueadura, respectivamente), além dos conteúdos sobre métodos contraceptivos no geral, como pílulas, preservativos, dispositivos intrauterinos, entre outros. Destas, três peças foram escolhidas para o uso na pesquisa (figuras 5, 6 e 7).

Dado o interesse em investigar a retenção de informação o mais próximo possível de um cenário verídico, optou-se no estudo por usar peças gráficas de fontes reais, mesmo que o conteúdo em si seja diferente entre estas. Este artigo não pretende, no entanto, adentrar nos pormenores procedimentais da pesquisa realizada, considera-se necessário colocar apenas que o experimento preteriu o uso de um mesmo conteúdo em diferentes linguagens sob o uso de materiais reais, alinhando-se com os objetivos da pesquisa.

As peças escolhidas apresentam linguagens gráficas diferentes entre si, principalmente no que se refere ao modo de simbolização da informação, foco do estudo. A peça 01 apresenta configuração linear interrompido e simbolização verbal-numérica e pictórica. 
Figura 5: Peça gráfica 01. Fonte: Portal Drauzio Varella'.

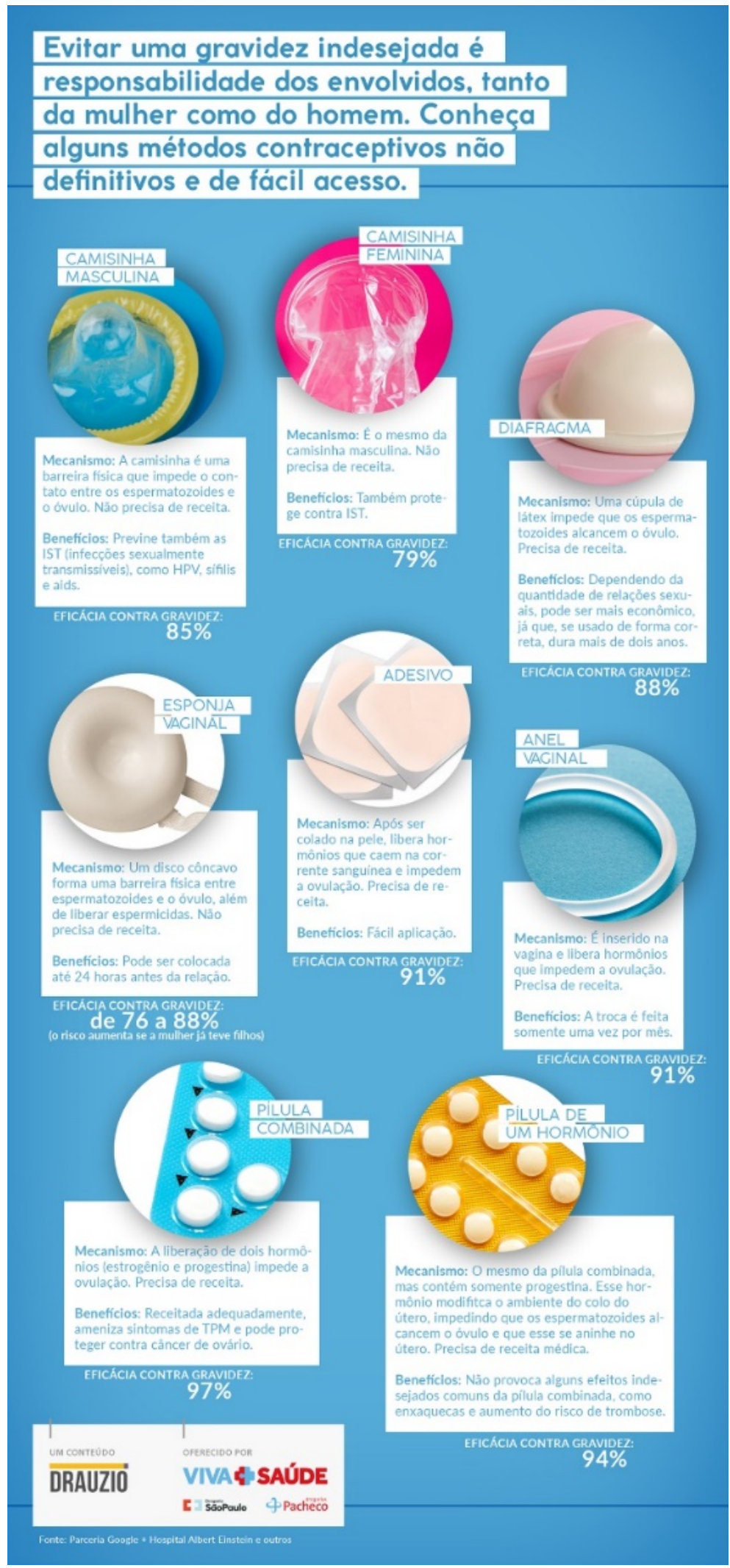

\footnotetext{
${ }^{1}$ Disponível em: <https://drauziovarella.uol.com.br/infograficos/principais-metodos-anticoncepcionais-de-facil-acessoinfografico/>. Acesso em: 28 jun. 2020.
} 
Já a peça 02 é colocada como configuração de leitura linear, e, desconsiderando as margens decorativas, possui simbolização prioritariamente verbal-numérica.

Figura 6: Peça gráfica 02. Fonte: Ministério da Saúde².
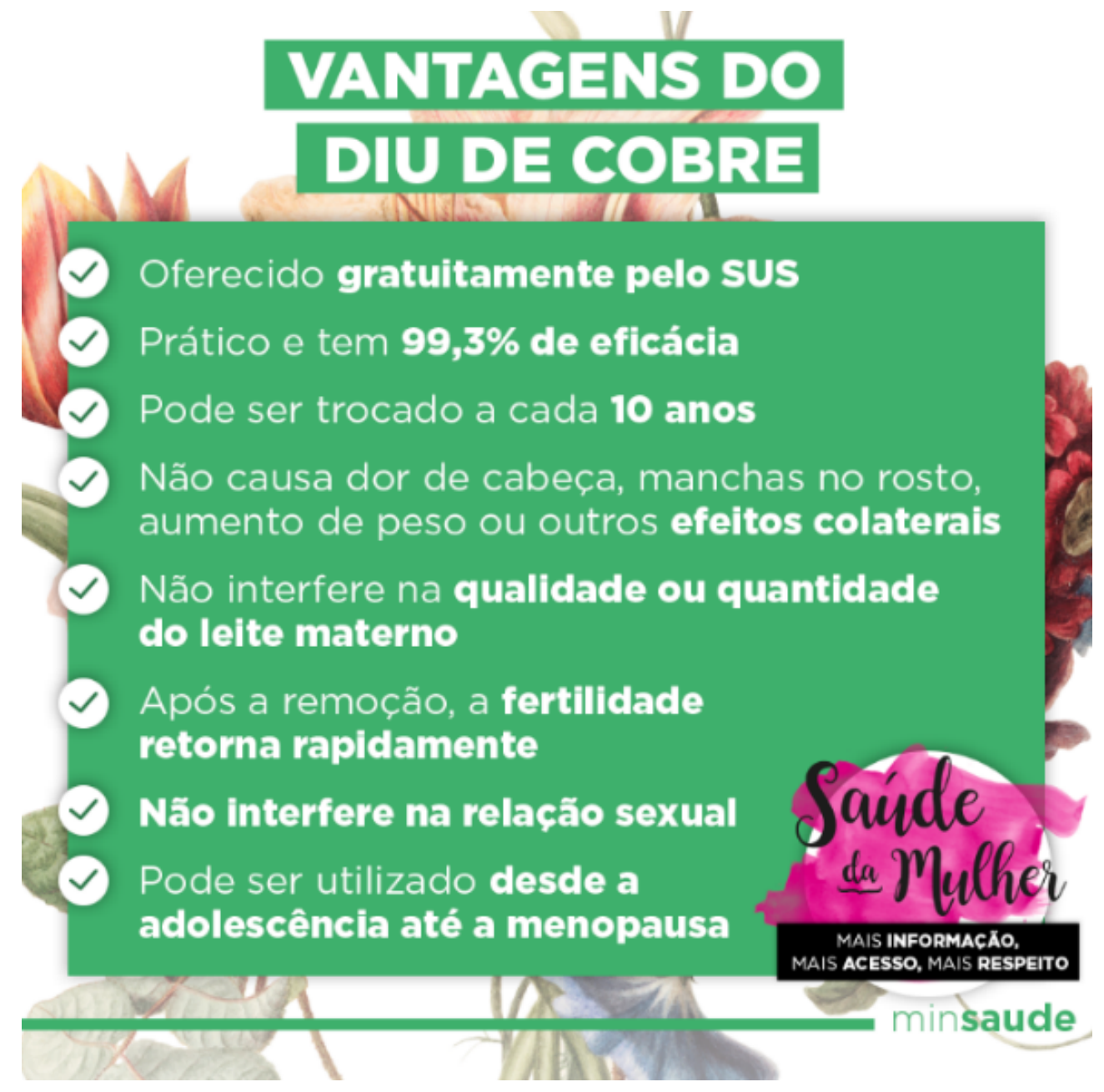

Por fim, a peça 03 se configura com layout aberto e linear, orientando hierarquia de informações, e possui simbolização verbal-numérica, pictórica e esquemática da informação.

\footnotetext{
${ }^{2}$ Disponível em: <https://www.facebook.com/minsaude/photos/o-diu-de-cobre-age-na-destruição-dos-espermatozoidessendo-um-método-contracepti/1527332303952047>. Acesso em: 28 jun. 2020.
} 
Figura 7: Peça gráfica 03. Fonte: Revista Saúde ${ }^{3}$.

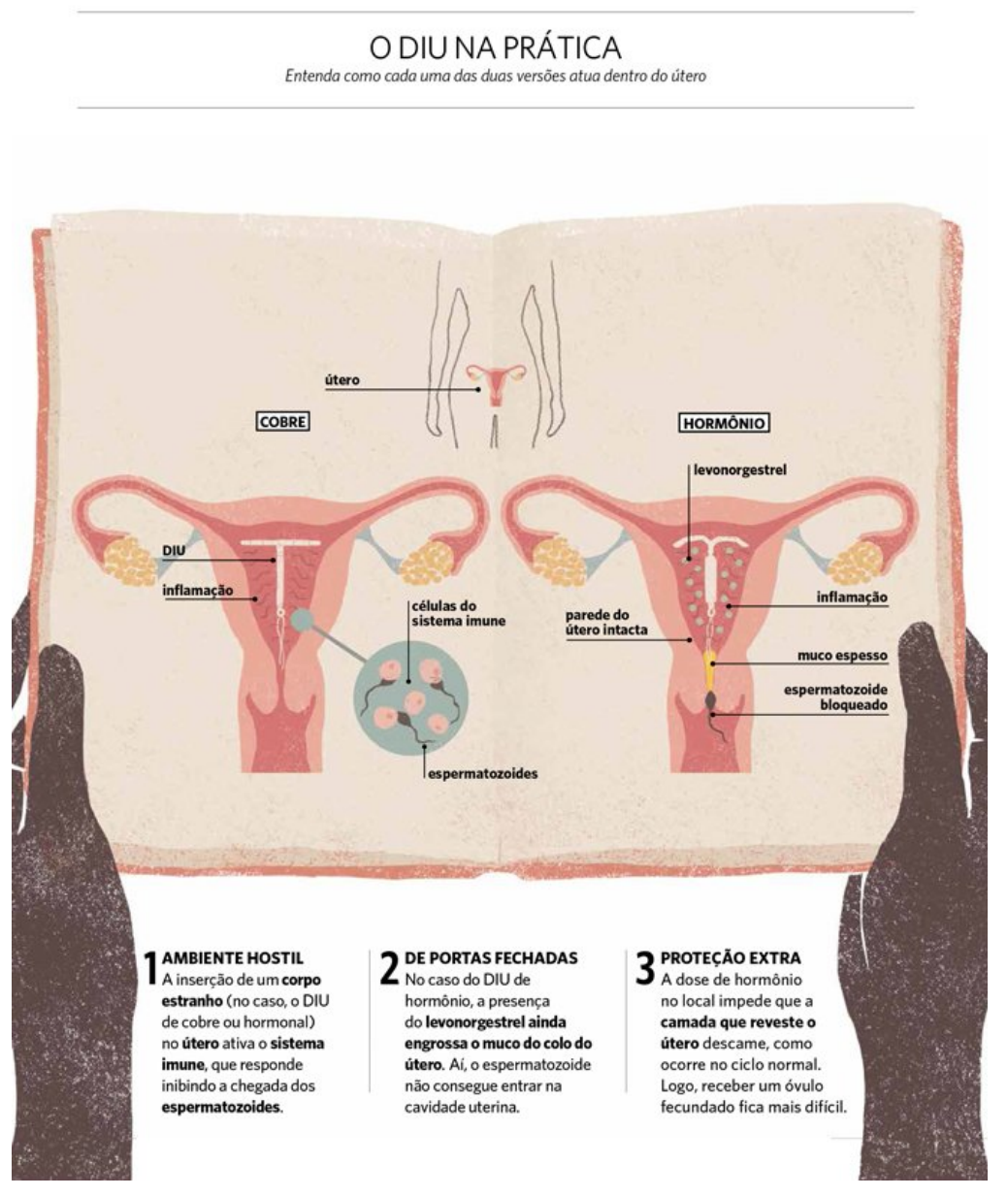

O público definido para esta pesquisa - pessoas do sexo feminino adultas jovens - se enquadra em um dos grupos de risco para gravidez não-planejada de acordo com Iseyemi et al. (2017). O protocolo da pesquisa foi usado com 29 participantes válidas, tendo onze visto a peça 01 , nove participantes visualizaram a peça 02 , e a peça 03 tendo sido vista por nove voluntárias. Isso a fim de sinalizar a performance de cada peça gráfica quando comparadas entre si. Esta escolha também objetivou evitar que a pessoa voluntária pudesse confundir os conteúdos se visualizasse todas as peças ou prolongar o tempo do experimento, prejudicando o desempenho da entrevista.

O experimento ocorreu em duas etapas principais, uma de visualização da peça gráfica definida para cada participante, com captação do rastreamento ocular destas, dentro do tempo máximo de 90 segundos. Esta etapa de visualização das imagens ocorreu com uso do equipamento Eye-Tracker SMI (figura 8), disponibilizado pelo NGD-LDU/UFSC, com acompanhamento de equipe preparada para uso correto deste. O equipamento se compõe de uma armação de óculos leve com elástico para fixação na cabeça e permite colocação de lentes de grau para usuários que precisem de lentes corretivas para visão.

${ }^{3}$ Disponível em: <https://saude.abril.com.br/medicina/tudo-sobre-o-diu/>. Acesso em: 28 jun. 2020. 
Figura 8: Eye-tracker SMI. Fonte: NGD-LDU, $2019^{4}$.

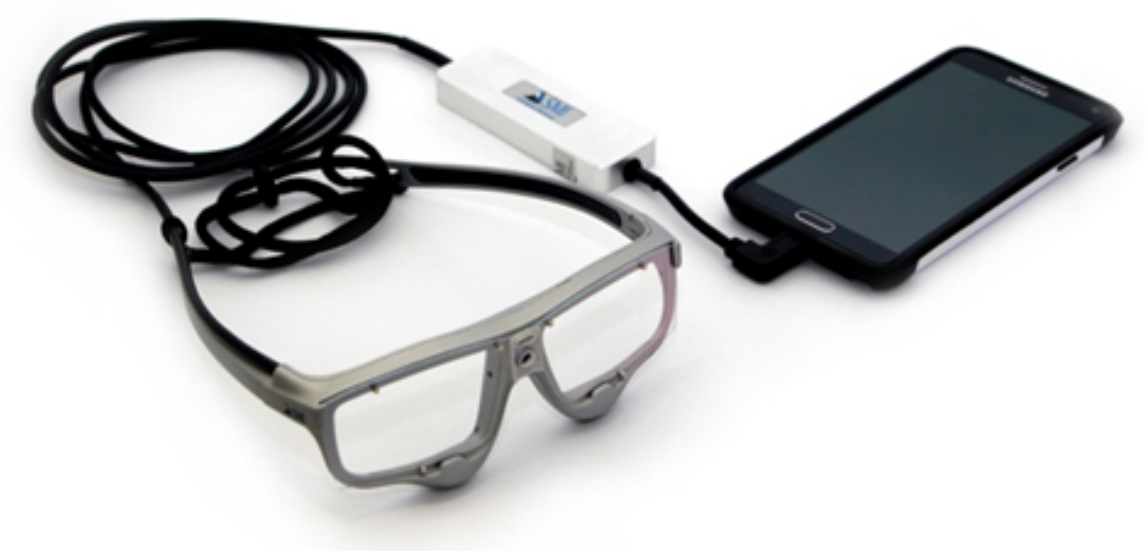

Após esta etapa, a pessoa voluntaria era deixada em uma sala de espera intermediária, planejada para relaxar e distrair por, pelo menos, 20 minutos. O ambiente era climatizado, contava com revistas, café, petiscos e assentos confortáveis. Transcorrido o tempo de espera, as pessoas eram convidadas para outra sala, onde foram realizadas as entrevistas semiestruturadas individualmente, com privacidade. Esta entrevista contava com algumas perguntas-chave preparadas anteriormente de acordo com cada peça gráfica estudada, isto para avaliar se as participantes haviam retido determinadas informações dispostas na peça em específico. No entanto, também houve espaço para comentários espontâneos em cada entrevista, o que, como será visto à frente, foi um ponto-chave para a exploração deste fenômeno cognitivo entre a percepção e a retenção de informação, permitindo impressões que poderiam não emergir perante um teste puramente objetivo do quanto havia sido retido de informação.

$\mathrm{Na}$ aplicação do teste, foram entrevistadas exclusivamente pessoas do sexo feminino (pessoas com útero), dentro da faixa etária de 18 a 21 anos, porém houve diferentes sexualidades apresentadas. Algumas participantes se relacionavam com outras pessoas do sexo feminino (fosse no momento, fosse exclusivamente), não havendo nestes casos o risco de gravidez. Houve o levante das questões de prevenção de IST em sexo entre duas mulheres e o levante da educação sobre contracepção para mulheres que necessitem do uso de métodos hormonais para fins terapêuticos, por exemplo, para redução de sintomas relacionados à endometriose. Isto era esperado, por isto não foi feita a discriminação por identidade de gênero (apenas por sexo) e nem por orientação sexual para inclusão no teste, considerando que mulheres de todas as sexualidades podem utilizar métodos hormonais para fins terapêuticos, e educação sexual no geral pode beneficiar inclusive a vida sexual destas se adaptada ao público.

${ }^{4}$ Disponível em: <http://ngd.ufsc.br/eye_tracking>. Acesso em: 26 jun. 2020. 


\section{Resultados}

Os dados coletados pelo Eye-Tracker foram analisados por meio do software BeGaze, disponibilizado pela equipe do NGD-LDU/UFSC. No software é possível visualizar os dados agrupados de cada imagem, delineando o trajeto do olhar das pessoas pelo objeto visto, o tempo de visualização em cada área deste objeto e onde os olhares se concentraram, entre outros. Aqui, destacaram-se o mapa de calor e o caminho do olhar.

O mapa de calor das peças (figura 9) delimita onde o olhar das participantes se condensou em cada peça gráfica. As áreas em vermelho são regiões onde o olhar se concentrou mais vezes e/ou por mais tempo. Indo da cor vermelha para amarelo e por fim verde para representar a concentração dos olhares, quanto mais distribuída e esverdeada a área, mais dispersa foi a visualização.

Figura 9 - Mapa de calor de todos participantes nas peças gráficas do estudo. Fonte: Arquivo da pesquisa, 2020.
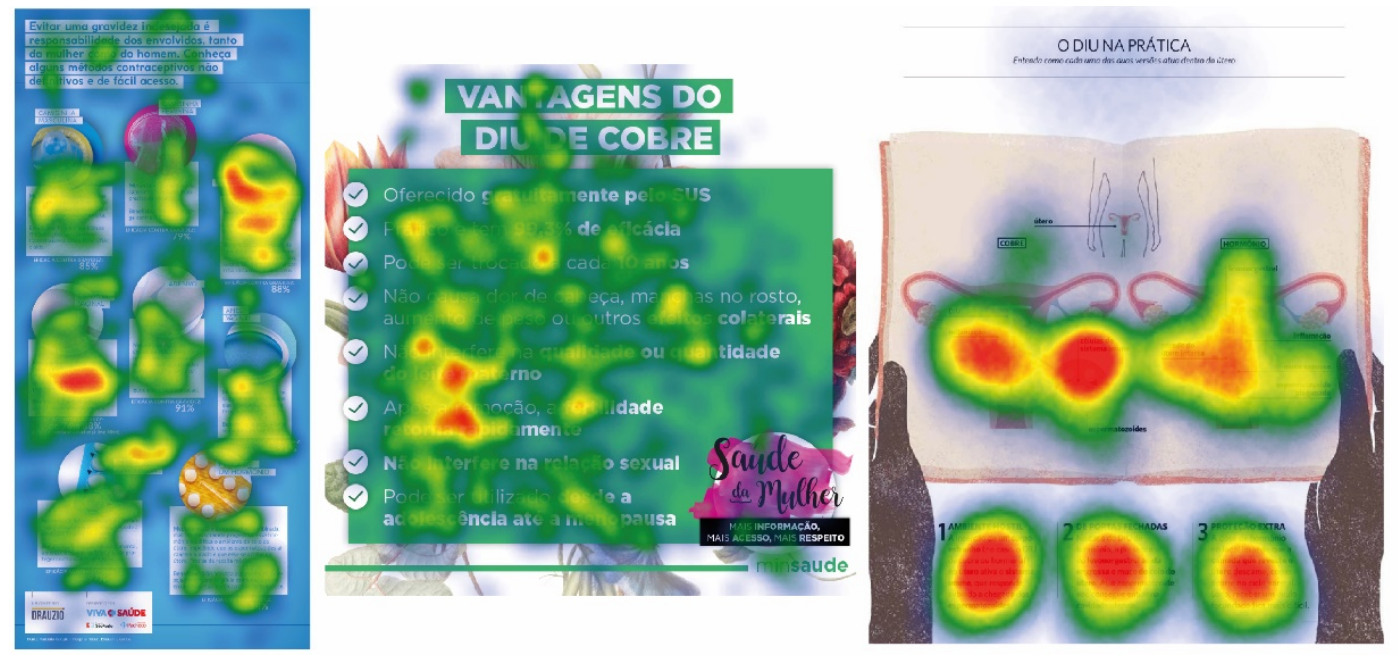

O mapa de calor sugere que a configuração do material gráfico afeta a visualização das informações. Na peça à esquerda, nota-se que o olhar das pessoas foi dispersado pela área da peça gráfica, havendo uma pequena predominância do olhar em duas fotografias, estas sendo dos métodos diafragma e esponja contraceptiva - que, posteriormente nas entrevistas, foram itens lembrados com frequência por serem desconhecidos para as participantes e, por isto, captaram maior atenção. Reforçando o que é percebido no mapa de calor, durante as entrevistas algumas voluntárias relataram sentir "confusão" ou "excesso" de informações não sabendo exatamente "para onde olhar" quando visualizaram a peça.

Na peça gráfica ao centro da figura 9, de autoria do Ministério da Saúde, o olhar ainda se registrou distribuído por quase toda área da imagem. Muito provavelmente, consequência da leitura obrigatória dos dados apresentados, que foram dispostos em formato de lista. Os pontos em negrito destacados do texto centralizados na peça conseguiram reter mais o olhar. Isto se mostrou presente nas entrevistas, visto que um dos dados mais relembrados pelas participantes desta imagem foi o fato do DIU de cobre não interferir no aleitamento materno, 
sendo esta informação localizada abaixo de uma das áreas em vermelho (indicando alta fixação dos olhares).

Já a terceira peça, de autoria da Revista Saúde, mostra um olhar direcionado e consistente das informações presentes. As áreas em vermelho demarcam o olhar predominante sobre os textos organizados abaixo e as ilustrações acima. O mapeamento do caminho do olhar (figura 10) nas peças reforça o que é notado pelo mapa de calor, como pode ser visto abaixo:

Figura 10 - Caminho do olhar de todas as participantes nas peças gráficas do estudo. Fonte: Arquivo da pesquisa, 2020.
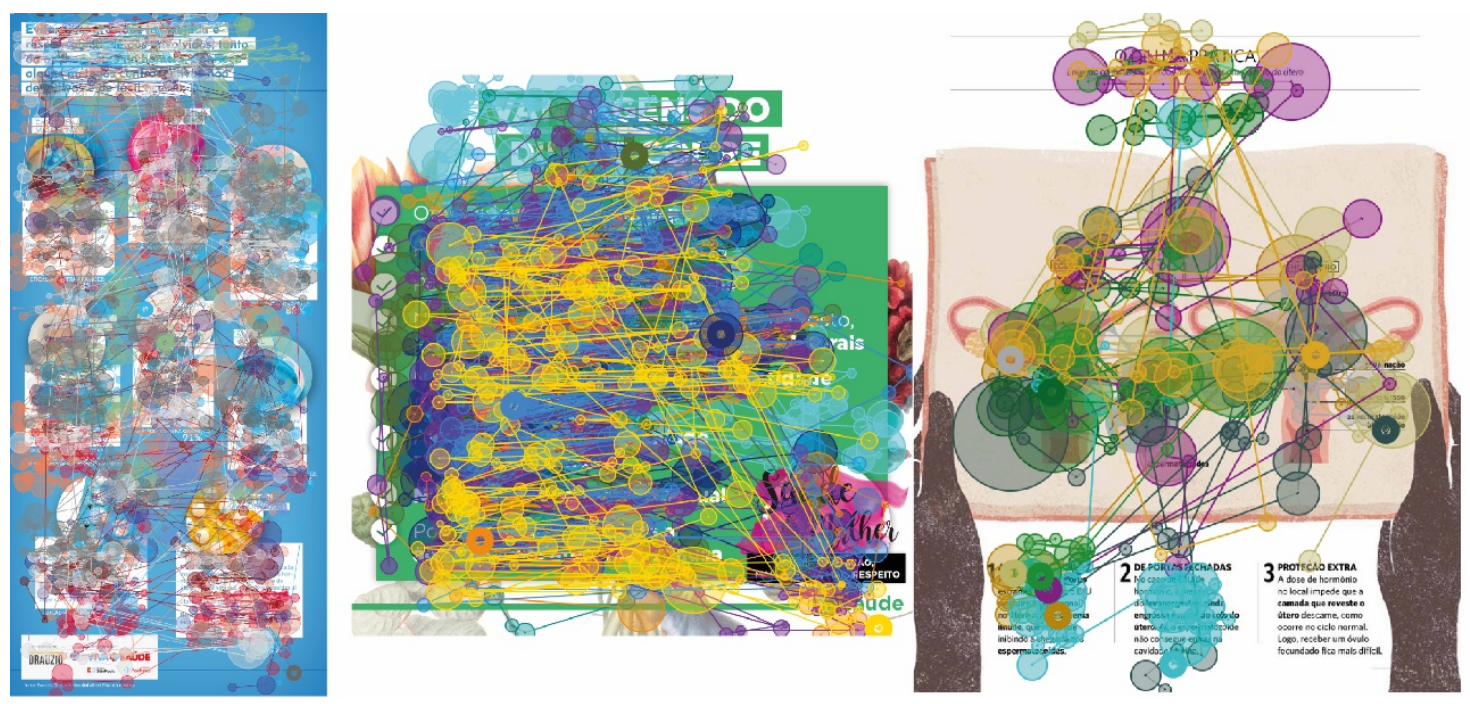

Ainda comentando sobre a peça gráfica 3 (à direita), que utiliza linguagem esquemática e pictórica de auxiliares na configuração de layout, esta demonstrou ter um fluxo de leitura bem demarcado, enquanto as outras peças apresentaram olhar mais disperso. Nesta peça, há o registro ocular da leitura intermitente entre figura e texto para ir se absorvendo o conteúdo em partes, movimento que foi confirmado em algumas entrevistas. Além disso, nota-se que a peça de autoria do site Drauzio Varella (peça 1, à esquerda) mostra um registro com olhar não só disperso como também breve, já que os círculos demarcadores de tempo de fixação do olhar são reduzidos e de tamanho similar ao longo da peça.

A coleta de dados do ET apresentou um panorama de cada peça gráfica, mas é na análise das entrevistas, a partir do que foi narrado pelas usuárias, que os detalhes de como as funções cognitivas se mesclam foi destacado.

Nas entrevistas, a peça gráfica 03 (figura 7) demonstrou facilitar a recordação dos conteúdos pelas usuárias que recorriam ao layout para recobrar memórias. Por exemplo, uma participante inicialmente não conseguia se recordar do conteúdo visto, porém conforme foi sendo questionada começou a recobrar a configuração visual da peça e, com isto, recuperar as informações vistas. Outra participante também demonstrou a utilização desse recurso cognitivo ao descrever que o DIU de cobre e o SIU hormonal causam uma inflamação no útero e que isto era possível de ser percebido por um "inchaço" nos desenhos dos úteros. Ela também reconheceu os círculos brancos presentes entre as margens da cavidade uterina e o dispositivo 
na ilustração da direita como os hormônios liberados pelo SIU, informação presente que era reforçada por linguagem textual e pictórica.

As demais peças estudadas obtiveram mais comentários negativos do que positivos por parte das entrevistadas, que diziam não verem atratividade nas imagens. Estas peças foram, em suma, julgadas como "feias e desinteressantes" pelas participantes, além da peça 01 , também ter sido julgada como "confusa" (o que já foi comentado e reforçado no mapa de calor).

Dadas as condições do delineamento desta pesquisa, que buscou explorar a performance da retenção de informação de materiais gráficos já existentes no meio estudado, não se considerou plausível a comparação inflexível destas peças entre si, mesmo com o conteúdo similar. As análises postas e comparações feitas objetivaram balizar as performances e desempenho destes materiais no experimento proposto. $E$ isto com propósito de maior entendimento sobre como as diferentes linguagens gráficas usadas nestas mídias poderiam afetar a atenção, compreensão e, principalmente, a retenção da informação por parte das usuárias. A análise de dados do Eye-Tracker com as entrevistas mostrou que, considerando a peça, sua linguagem gráfica e como ela afeta as funções cognitivas que pode - atenção, compreensão, e retenção da informação - a peça gráfica da Revista Saúde (figura 7) se ressaltou perante as demais.

No caso da retenção de informação, o processo depende de fatores internos, porém para esta retenção ocorrer a pessoa precisa primeiro perceber esta informação em seu contexto e compreendê-la. Isto posto, é considerável que as peças gráficas 1 e 2 (figura 5 e 6 , respectivamente) teriam maior dificuldade em atingir o público estudado. Aquela, por dispersar o olhar e confundir os usuários, esta por atrair pouca atenção.

A informação ser compreensível nem sempre significa que será memorável - apesar de isto ser um importante começo. Esta exploração revelou indícios importantes sobre a melhora da retenção de informação a partir de peças gráficas que utilizem linguagem gráfica verbal, pictórica e esquemática. Isto pois as informações ficam mais atrativas e compreensíveis, facilitando a codificação e armazenamento das informações apresentadas, além da possibilidade de reforço de informações importantes em mais de uma linguagem, como já foi comentado. No entanto, outras importantes questões foram percebidas no decorrer da pesquisa, comentadas a seguir.

\section{Considerações}

Além da avaliação da retenção de informações de acordo com a linguagem gráfica de cada peça, esta exploração permitiu a percepção de outros elementos expressivos. Uma recorrência que se destacou foi a lembrança de informações latentes que eram acessadas perante um novo dado visto ou um dado reforçado. Algumas participantes recordavam de aulas de biologia ou educação sexual na escola, outras de conversas com ginecologista, outras ainda de conversas com amigas e familiares, e relacionavam o que já sabiam (ou imaginavam) com o que havia sido apresentado de novo ou reforçado na peça vista. Estes casos enfatizam o que 
foi apontado sobre a memória agir também como formadora de conhecimento ao influenciar como percebemos novas informações (Mourão Júnior \& Faria, 2015; Sternberg, 2010; Correa \& Gorenstein, 1988).

A ocorrência da recordação de aprendizados anteriores gera o questionamento: teriam as peças gráficas maior desempenho em cativar a atenção e maior desempenho em reter informações caso houvesse uma consideração anterior, no planejamento da produção do material, sobre o que o público que se almeja atingir já sabe ou já pensa sobre determinado conteúdo? Seria, por exemplo, mais assertivo produzir um material gráfico sobre o DIU de cobre para a persona de uma jovem adulta sem vida sexual ativa se fosse ponderado antes o que esta sabe e pensa sobre o método?

Outra percepção que se mostrou relevante foi como a abordagem gráfica e narrativa usada nos conteúdos pode interferir em variáveis internas de um público. Foi notável nas entrevistas como o tema tratado pelas peças (educação sexual) pode ser intimidador ou deixar pessoas retraídas. Uma participante chegou a confessar não pesquisar sobre contracepção porque os pais não poderiam saber que ela tem vida sexual ativa - a sensação de proibição gerou, em certas entrevistas, retração em conversar sobre o assunto.

Felizmente, as entrevistas desenrolaram-se sem grandes empecilhos além de momentos de timidez ou receio em abordar ou falar sobre contracepção, sexo, saúde sexual ou partes do sistema sexual. Era perceptível pelo tremor da voz, ruborização facial ou gesticulação que algumas entrevistadas sentiram leve desconforto - isso quando elas não verbalizavam o próprio constrangimento, e nestes momentos era necessária sensibilidade para guiar a entrevista sem intensificar estes incômodos.

Em contrapartida aos casos de timidez e retração, houve participantes, com ou sem vida sexual iniciada, conversando com tranquilidade sobre os temas abordados. Estas, em geral, tinham algum repertório de educação sexual anterior, por vezes formado pela própria família apresentando opções contraceptivas, e o assunto estava dentro de seus limiares de conforto emocional.

Além do uso da linguagem gráfica verbal-numérica, pictórica e esquemática, notou-se que a percepção de pormenores cognitivos e emocionais podem ser relevantes para o planejamento de peças informativas sobre educação sexual. Ainda que estes pormenores sejam fatores subjetivos do indivíduo, é possível planejar e adequar a linguagem visual para o contexto cognitivo-emocional do público a quem se direciona a informação. Afinal, como foi visto, para uma informação ser memorizada, é preciso primeiro que esta seja atraente e compreensível. E a possibilidade de um material gráfico atrair, explanar e reforçar conteúdo deste tipo - e para quem - é a competência que cabe ao Design.

\section{Agradecimento}

Esta pesquisa foi realizada com apoio financeiro do PROMOP/UDESC e da Coordenação de Aperfeiçoamento de Pessoal de Nível Superior - Brasil (CAPES). 
Ao Núcleo de Gestão de Design e Laboratório de Design e Usabilidade da Universidade Federal de Santa Catarina (NGD-LDU/UFSC), nosso muito obrigada pela colaboração na pesquisa.

\section{Referências}

CORREA, Denise Dias; GORENSTEIN, Clarice. Bateria de testes de memória (I): critérios de elaboração e avaliação. Arquivos Brasileiros de Psicologia, v. 40, n. 2, p. 24-35, 1988.

ISEYEMI, Abigail; MCNICHOLAS, Colleen; PEIPERT, Jeffrey F.; ZHAO, Qiuhong.

Socioeconomic status as a risk factor for unintended pregnancy in the contraceptive CHOICE Project. Original Research. p. 1-7. 2017

KATZ, Joel. Designing Information: human factors and common sense in information design. New Jersey, Published by John Wiley \& Sons, Inc. Hoboken, 2012.

MOURÃO JÚNIOR, Carlos Alberto; FARIA, Nicole Costa. Memory. Psicologia: Reflexão e Crítica, v. 28, n. 4, p. 780-788, 2015.

PETTERSSON, Rune. It Depends: Principles and Guidelines. Viena: Internacional Institute for Information Design, 2012.

PREECE, Jennifer; ROGERS, Yvonne; SHARP, Helen. Design de Interação. Bookman Editora, 2013.

REDIG, Joaquim. Não há cidadania sem informação, nem informação sem design. Revista Brasileira de Design da Informação, v. 1, n. 1, p. 58-66, 2004.

SHEDROFF, N. Information interaction design: a unified field theory of design. In: JACOBSON, Robert (ed.). Information design. Cambridge (MA): The MIT Press, 1999.

STERNBERG, Roberto J.. Psicologia Cognitiva. São Paulo: Cengage Learning, 2010.

TWYMAN, Michael, Using pictorial language: a discussion of the dimensions of the problem. In T. M. Dufty and R. Waller. (eEds.) Designing usable texts. Orlando, Florida: Academic Press, p. 245-312. 1985.

TWYMAN, Michael. A schema for the study of graphic language. KOLERS, P.A. \&; WROSTAD, M.E. \&; BOUMA, H. (Eds.), In: The processing of visible language, vol. 1, Plenum, New York, pp. 117-150. 1979.

\section{Sobre as autoras}

Caroline Winkelmann, Ms., UDESC, Brasil, <carolwnk@gmail.com> Gabriela Botelho Mager, Dra., UDESC, Brasil, <gabriela.mager@udesc.br> 